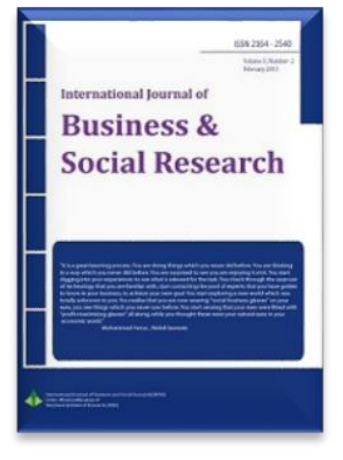

\title{
Moral Implications of Leadership - Transformative Insights
}

\author{
Feng Xu', Cam Caldwell², Verl Anderson 3
}

\begin{abstract}
In this paper we examine the correlations between Lawrence Kohlberg's six stages of morality and Transformative Leadership, a new morally-based approach to leadership. Using survey of students, faculty members, and staffs at a South Florida private university we present evidence that there is a clear relationship between an individual's self-described leadership perspectives and the stages of Kohlberg's moral development model. Our paper provides five significant contributions to the literature about leadership and its moral role and enables scholars and practitioners to understand more completely the relationships between leadership and moral behavior.
\end{abstract}

Keywords: Commitment, Kohlberg's six-stage moral development, morality, transformative leadership. Available Online: 16-04-2016.

This is an open access article under Creative Commons Attribution 4.0 License, 2016.

\subsection{INTRODUCTION}

To earn the trust of followers, leaders must demonstrate a highly moral commitment to the welfare of others if they wish to retain trust (Cameron, 2011). Despite the inherent logic in such a statement, the scholarly literature offers little empirical evidence about the relationship between a leader's selfperspective about their leadership philosophy and the moral implications of that philosophy. Recently, Caldwell and colleagues (Caldwell, et al., 2012) introduced a new model of "transformative leadership" that focuses on the duties owed by leaders, incorporating ethical components of six highly regarded leadership perspectives. Exploring the relationships between the duties of leadership and their moral focus can improve scholars' and practitioners' understanding of the relationships between leadership and leaders' moral duties to others (cf. Hosmer, 2011).

The purpose of this paper is to identify how the leadership perspectives of transformative leadership relate to Kohlberg's (1981) six stages of moral development. We explain Kohlberg's moral development model and the ethical focus of the perspectives of transformative leadership, presenting seven hypotheses about the relationship between transformative leadership and the Kohlberg model. After

\footnotetext{
${ }^{1}$ School of Business Administration, Georgia Southwestern State University, Americus, GA 31709, E-mail: feng.xu@gsw.edu

${ }^{2}$ School of Business and Communications, Dixie State University, St. George, UT 84770., E-mail: cam.caldwell@dixie.edu

3 School of Business and Communications, Dixie State University, St. George, UT 84770. E-mail: verl@dixie.edu
} 
describing the research method to test these hypotheses, we present the research results and conclude with the contributions of this paper.

\subsection{LEADERSHIP AND MORAL DEVELOPMENT}

Leader effectiveness reflects the leader's ability to be perceived as morally intelligent (Lennick \& Kiel, 2007), capable of making justifiable ethical decisions (Hosmer, 2011), and congruent in matching organizational claims with their own personal values (Schein, 2010). This credibility (Kouzes \& Posner, 2011 ) is the key to building the high trust cultures critically important to compete in today's global economy (Pfeffer, 1998; Christensen, 2013, Cameron, 2011).

Lawrence Kohlberg (1981), a noted psychologist and educator, developed a six-stage model of moral development that identified the basis by which individuals make moral choices. Kohlberg's model is a useful framework for understanding ethical criteria that motivates personal conduct (Jackson et al., 2013), including the moral perspective of leaders. We briefly describe how each stage of Kohlberg's model explains the moral implications of human behavior and ethical decision-making.

The assumption inherent in Kohlberg's (1981) model is 1) centered on his belief that justice is at the center of moral reasoning and 2) that the foundation for one's perspectives about justice reflect the degree to which individuals define moral responsibilities. Kohlberg's model includes three levels and six stages, with each stage reflecting a higher level of moral maturity (Weber, 1991). Reed (2008, p. 359) explained that moral maturity progressed "through a succession of increasingly cooperative interaction structures" resulting in an increasingly comprehensive recognition of moral obligations. The following is a brief summary of Kohlberg's model of moral development.

\subsection{LEVEL ONE: PRE-CONVENTIONAL MORALITY}

Level One views morality in terms of self-gratification and self-interest and is driven by reliance upon external rules which determine outcomes affecting each individual. Although individuals are motivated to avoid punishment and seek benefits, these motivations predominate in guiding the actions of those who are at Level One (Kohlberg, 1981).

Stage One: Obedience and Punishment - Individuals obey rules and view those rules as fixed and absolute. People are motivated by fear of being punished rather than by other goals (Minnameier, 2006).

Stage Two: Individualism and Exchange - The motivation in this stage optimizes personal benefit. Individuals in this stage "do what is right to serve their own needs and interests" (Baucus \& BeckDudley, 2005, p. 357).

\subsection{2 \\ LEVEL TWO: CONVENTIONAL MORALITY}

This level views moral duty in context with relationships with others, defining morality in terms of norms and conventions that are fundamental elements of society (Kohlberg, 1981). The individual motivated at this level uses "an external frame of reference but is doing so on a more cognitively complex level" (Jackson et al., 2013, p.235).

Stage Three: Interpersonal Relationships - Individuals honor peer group social conventions and rules as their standard for behaviors. Their motivation is to be perceived by others as trustworthy to create mutual long-term relationships (Kracher \& Marble, 2008, p. 506).

Stage Four: Maintaining Social Order - Individuals obey social order rules to honor "obligations as mandated by the community" to comply with societal expectations and be accepted (Sachdeva et al., 2011, p. 163). 
This level defines moral duty as a higher set of duties than simply the obligations owed to society at large. Moral choices must be based upon principles and values that define rules and norms but supersede those rules and norms themselves (Kohlberg, 1981). Moral values and principles have "validity and application apart from the authority of the groups and persons holding these principles" (Weber, 1991, p. 296). The goal of this level is "the principled pursuit of universal good" (Reed 2008, p. 367).

Stage Five: Social Contracts and Individual Rights - This stage values opinions and beliefs that frame standards of behavior within the context of a culture or society (cf. Reed, 2009, p. 305306). Laws are social contracts between an individual and a society or group, rather than as unbending standards of truth (Kohlberg, 1981).

Stage Six: Universal Principles - Moral choices follow universal principles and reasoning which override other standards of society. Universal principles are based on the issues of justice, reciprocity, and the dignity of individuals (Moroney, 2006). These principles serve as moral hypernorms (Donaldson \& Dunfee, 1999, p. 215-220) universally accepted across cultures (cf. Lewis, 1980, p. 3-5).

According to Kohlberg (1981), people rarely advance beyond the second level of moral development and few individuals consciously consider moral principles in decision-making.

\subsection{THE SIX PERSPECTIVES OF TRANSFORMATIVE LEADERSHIP}

Although transformative leadership is a new model of ethical leadership, its roots are well-established in its integration of six highly regarded leadership perspectives (Caldwell, 2012). Transformative leadership is "an ethically-based leadership model that integrates a commitment to valued outcomes by optimizing the long-term interests of stakeholders and society and honoring the moral duties owed by organizations to their stakeholders (Italics in the original)" (Caldwell et al., 2012, p. 176). It integrates the ethical elements of transformational, charismatic, principle-centered, level 5, servant, and covenantal leadership (Caldwell, 2012). Figure 1 identifies these six leadership perspectives and their contribution to transformative leadership.

Figure 1: Transformative leadership

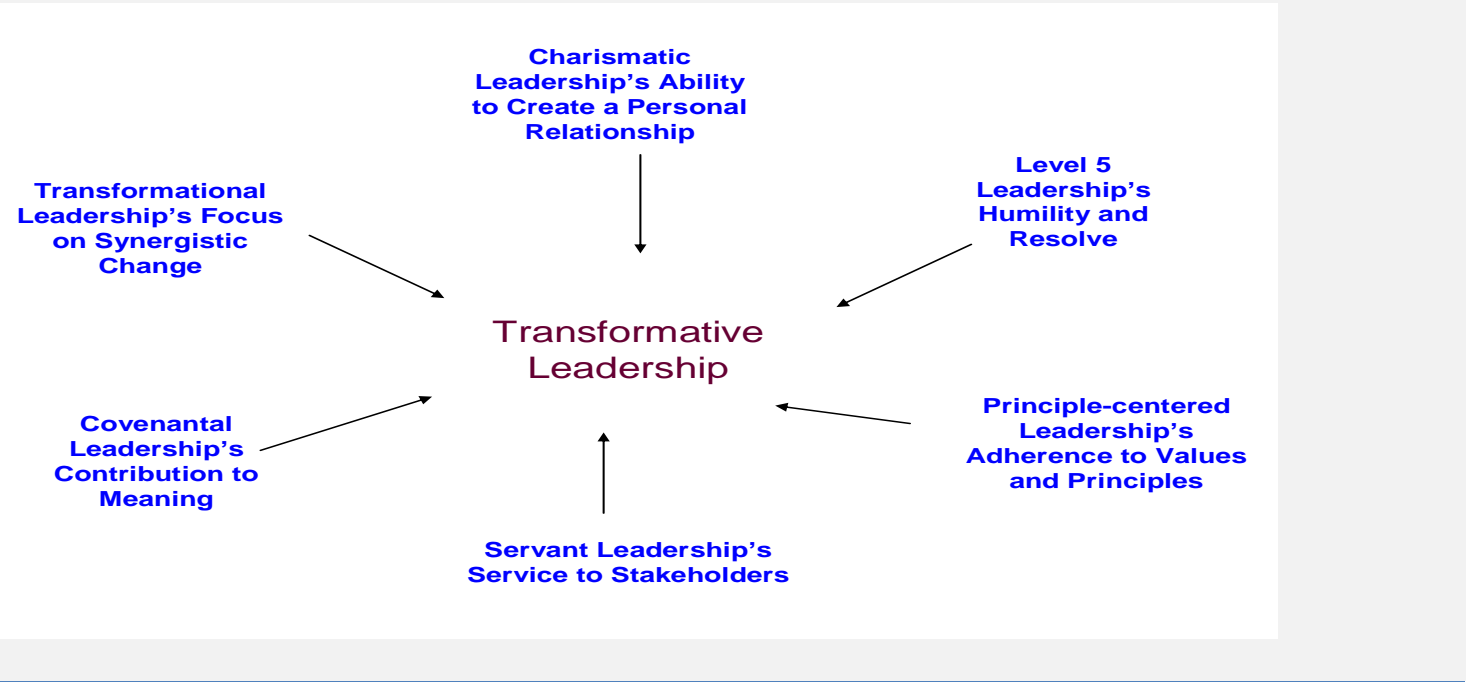

\subsection{TRANSFORMATIONAL LEADERSHIP'S FOCUS ON SYNERGISTIC CHANGE}

Transformational leadership emphasizes the leader's role in implementing synergistic change while honoring the responsibility to help employees to also grow (Lussier \& Achua, 2013, p. 340-342; DuBrin, 2013, p. 83-96). Transformational leaders pursue excellence as a moral duty requiring creating synergistic solutions that benefit both individuals and the organization in the pursuit of greatness (Cameron, 2011). 
Transformational leadership incorporates four elements: 1) individualized consideration by which a leader meets followers' needs and supports their self-development; 2) intellectual stimulation to allow team members to challenge organizational assumptions and to engage in creativity; 3 ) inspirational motivation establishing high standards and support in the pursuit of goals; and 4) idealized influence modeling ethical behavior in earning the trust of others (Bass, 1998). Transformational leadership integrates these elements to transcend individual self-interest and create powerful benefits for the organization and for its members (Grant, 2012).

Transformational leaders challenge the status quo to adapt to the needs of a changing world (Warrick, 2011). Addressing the demands of change is a critical duty of leadership (Bennis \& Nanus, 2007). Transformative leadership shares this commitment to synergistic change as a moral duty. The following hypothesis reflects transformational leadership's commitment to achieving excellence.

$\mathbf{H}_{1}$ : Individuals rating themselves higher with regard to transformational leadership will also rate themselves higher in Kohlberg's fifth stage of moral development than those who rate themselves lower in transformational leadership.

\subsection{COVENANTAL LEADERSHIP'S CONTRIBUTION TO MEANING}

Covenantal leadership requires leaders to be an exemplar, a teacher, and the creator of new meaning as a covenantal duty (Pava, 2003). Covenantal leadership "is an attempt to unleash the great human potential which is often dormant and silent" within most organizations (Pava, 2003, p.26). The covenantal leader believes that new meaning unlocks human potential and empowers people to learn, grow, and improve (Pava, 2003).

Covenantal leaders create a learning culture, promote creativity and continuous improvement, and pursue new truth (cf. Senge, 2006). Identifying truth reflects the applied ethical perspective of covenantal leadership (Pava, 2003), looking beyond conventional thinking that is most often the cause of organization dysfunction (Pfeffer, 1998, Ch. 1). The second hypothesis reflects covenantal leadership's commitment to the pursuit of truth.

$\mathbf{H}_{2}$ : Individuals rating themselves higher with regard to covenantal leadership will also rate themselves higher in terms of Kohlberg's fifth stage of moral development than those who rate themselves lower in covenantal leadership.

\subsection{SERVANT LEADERSHIP'S SERVICE TO STAKEHOLDERS}

Servant leadership is based upon "service to others and recognition that the role of organizations is to create people who can build a better tomorrow" (Parris \& Peachey, 2013, p. 378). Servant leaders believe that organizations must treat people humanely if those organizations are to reach their highest potential (Keith, 2012). Block (2013) explained that the duty of leaders was to treat employees as "owners and partners," providing them with the information necessary to succeed as key contributors to the organization while pursuing their own growth.

Servant leaders adopt an ethic of care that values individuals and considers relationships as critical to organizational success (cf. Gilligan, 1993). Servant leadership promotes a high trust organizational culture which increases personal commitment (Pfeffer, 1998), thereby enabling organizations to achieve their highest potential. Transformative leadership adopts this commitment as it seeks to serve both individuals and organizations in optimizing long-term wealth creation (Caldwell \& Hansen, 2010). The third hypothesis is consistent with servant leadership's commitment to the individual.

$\mathbf{H}_{3}$ : Individuals rating themselves higher with regard to servant leadership will also rate themselves higher in Kohlberg's third stage of moral development than those who rate themselves lower in servant leadership. 


\subsection{PRINCIPLE-CENTERED LEADERSHIP'S ADHERENCE TO VALUES AND PRINCIPLES}

Principle-centered leadership endorses universal principles which govern organizational and interpersonal relationships (Covey et al., 1999). Principle-centered leaders embrace universal truths defining duties and obligations of leaders that apply across national boundaries, cultures, and belief systems (Lewis, 2001). Principle-centered leaders honor the duties to do no harm, to create wealth in the present, and to create wealth long term (Lennick \& Kiel, 2007).

Principle-centered leadership conforms to a virtue-based Aristotelian ethical framework which expects leaders to adopt virtuous principles and values (Solomon, 1992). Transformative leadership applies this commitment to universal principles and values to honor duties owed to stakeholders (Caldwell et al., 2012). The fourth hypothesis reflects principle-centered leadership's commitment to guiding principles and values.

$\mathbf{H}_{4}$ : Individuals rating themselves higher with regard to principle-centered leadership will also rate themselves higher in rating Kohlberg's sixth stage of moral development than those who rate themselves lower in principle-centered leadership.

\subsection{LEVEL 5 LEADERSHIP'S HUMILITY AND RESOLVE}

Level 5 leadership combines personal humility with a fierce resolve to achieve optimal outcomes (Collins 2001). Collins (2001) found that great organizations were led by level 5 leaders who differentiated themselves from competitors by being fiercely committed but low-keyed leaders. Level 5 leaders give credit to others for successes, assume personal responsibility for failures, and focus their leadership efforts on helping the organization to succeed (Collins 2001). Collins (2001, p. 35) noted that level 5 leaders "look out the window to apportion credit to factors outside themselves when things go well ... (and) they look in the mirror to apportion responsibility, never blaming bad luck when things go poorly"

Schein (2013) also emphasized the importance of humility in leadership empowerment--manifest best when leaders listen and participate in dialogue with others. Level 5 leaders demonstrate an outcomebased ethical perspective with an emphasis on achieving optimal organizational success (Collins, 2008, p. 20). Transformative leaders pursue optimal outcomes while giving credit to others and demonstrating personal humility (Caldwell, 2012). Hypotheses five reflects the Level 5 leaders' personal humility and commitment to organizational success as morally-related duties.

$\mathbf{H}_{5}$ : Individuals rating themselves higher with regard to level 5 leadership will also rate themselves higher in Kohlberg's third level of moral development than those who rate themselves lower in level 5 leadership.

\subsection{CHARISMATIC LEADERSHIP'S ABILITY TO CREATE A PERSONAL RELATIONSHIP}

Charismatic leadership incorporates a leader's sense of personal mission which enables her/him to connect with others at a personal level (Lussier \& Achua, 2013, p. 363). Charismatic leaders create relationships based upon a personal connection that inspires and motivates others to join with them to accomplish a noble outcome transcending individual self-interests (Brown \& Trevino, 2006). As leaders passionately committed to a grand ideal, charismatic leaders pursue that ideal and motivate followers to go the extra mile in its pursuit (DuBrin, 2013, ch.3).

Individual members are fully empowered shareholders (Conger \& Kanungo, 1998). The ethical emphasis of charismatic leadership is virtue-based and utilitarian and creates personal connection with others (Hayibor et al., 2011). The sixth hypothesis reflects charismatic leadership's commitment to personal relationships in accomplishing a noble ideal.

$\mathbf{H}_{6}$ : Individuals rating themselves higher with regard to charismatic leadership will also rate themselves higher in Kohlberg's third level of moral development than those who rate themselves lower in charismatic leadership. 
Several scholars have suggested that an integrated leadership approach that deals with individuals in a multi-faceted way is more effective than those who offer piece-meal or partially integrated systems, policies, and programs (Pfeffer, 1998). Accordingly, our final hypothesis is that individuals who adopt transformative leadership's integration of all six of the leadership perspectives will have a greater commitment to Kohlberg's moral values.

$\mathbf{H}_{7}$ : Individuals rating themselves higher with regard to their transformative leadership combined score will also rate themselves higher in all six stages of Kohlberg's moral development model than those who rate themselves lower in transformative leadership.

\subsection{RESEARCH METHODOLOGY}

We surveyed randomly selected students, faculty and staff members at a South Florida private university. Among people who responded to the survey, $45 \%$ were male and $55 \%$ were female, $36 \%$ were Hispanic, $26 \%$ were African-American, 19\% were Asian, 16\% were Caucasian, and the remaining 3\% reported themselves as belonging to other ethnic groups. Respondents provided general demographic information without personal identification and the demographic composition of the respondents generally resembled that of the university. Each respondent ranked themselves on a ten-point Likerttype scale based upon 48 items which reflected their personal leadership perspectives and moral selfdescription. Factors measured the six leadership perspectives of transformative leadership and the six stages of the Kohlberg model and were content-matched with academic literature published on both topics.

Despite efforts to ensure the objectiveness of the survey administration, we acknowledge limitations in our study. Because transformative leadership is a relatively new model, there are opportunities to continue to improve the measurements of the six leadership perspectives used in the survey instrument. In addition, the ethical perspectives associated with leadership often overlap (Brady, 1999; Hosmer, 2011) as do elements of the six leadership perspectives (Caldwell, 2012). Survey results also may be limited in generalizability to the South Florida university culture. Despite these limitations, findings reported in this study suggest potential benefits associated with the moral nature of transformative leadership and provide a rationale for further research.

\subsection{FINDINGS AND DISCUSSION}

After excluding missing data, we collected 371 usable records for statistical analysis. Measurements of Kohlberg's moral development stages and the components of transformative leadership were obtained based upon respondents' judgments about their self-descriptions of the moral development stages and transformative leadership perspectives. The measurements obtained from the survey data are rankings of each factor surveyed. These rankings are not distributed according to a probability distribution. Nonetheless, as ordinal variables, rank correlation coefficients, such as Spearman's $\rho$ and Kendall's $\tau$, can be used to measure statistical association between ordinal variables (Agresti, 2010). Accordingly, measurements of factors were categorized into two levels, with a measurement rank/score higher than 66.67 percentile of all scored values for a factor assigned to the "Important" category, with lower scores assigned to the "Less Important" category.

Because Pearson's $\chi^{2}$ statistic analyzes the dependence of association between two categorical variables and is sensitive to sample size and because certain statistics based on concordant and discordant pairs sometime result in misleading conclusion, we used the odds ratio statistic $(\theta)$, as proposed by Agresti and Finlay (2009), for analyzing the association between factors. The odds ratio identifies the ratio of odds of rating each corresponding factor. For two factors positively associated, the odds ratio is larger than 1.0, while for negative associations it is less than 1.0. For large size samples, as in our research, Agresti and Finlay (2009) pointed out that the logarithm of the odds ratio, $\ln (\theta)$, approximately follows 
a normal distribution with zero mean and a standard deviation (s.d.) which can be calculated using the following equation,

$$
\text { s.d. }=\sqrt{\sum_{i=1}^{2} \sum_{j=1}^{2} \frac{1}{\text { frequency }_{i, j}}} .
$$

Therefore, a standard normal distribution statistic (z-statistic) can be calculated to test the significance of a positive or negative association between two factors.

For each of the hypotheses abovementioned, corresponding associations were first analyzed using Spearman's rank correlation coefficients and their p-values based on original ranking measurements. In addition, the asymptotic $z$ statistics and corresponding p-values are also calculated using categorized importance level measurements, which enable statistical tests on associations of the interest in a general format. Statistical results of the analysis are stated in Table 1 below, in which LP is the combined measurement of transformative leadership perspectives.

Table 1: Statistics of testing associations between moral development stages and transformative leadership perspectives

\begin{tabular}{|c|c|c|c|c|c|c|}
\hline \multirow[b]{2}{*}{ Factors } & & \multicolumn{3}{|c|}{ Odds Ratio Statistics } & \multicolumn{2}{|c|}{ Spearman Rank Correlation } \\
\hline & & $\theta$ ratio & $\begin{array}{r}\text { z- } \\
\text { statistic }\end{array}$ & p-value & $\begin{array}{c}\text { Correlation } \\
\text { Coefficient }\end{array}$ & $\mathrm{p}$-value \\
\hline Transformational & Stage 5 & 4.777 & 6.732 & 0.000 & 0.463 & 0.000 \\
\hline Covenantal & Stage 5 & 3.062 & 5.000 & 0.000 & 0.524 & 0.000 \\
\hline Servant & Stage 3 & 4.887 & 6.801 & 0.000 & 0.509 & 0.000 \\
\hline PrincipleCentered & Stage 6 & 4.080 & 6.270 & 0.000 & 0.544 & 0.000 \\
\hline Level 5 & Stage 3 & 2.613 & 4.334 & 0.000 & 0.480 & 0.000 \\
\hline Charismatic & Stage 3 & 5.989 & 6.647 & 0.000 & 0.542 & 0.000 \\
\hline LP & Stage 1 & 4.808 & 6.672 & 0.000 & 0.538 & 0.000 \\
\hline LP & Stage 2 & 3.800 & 5.818 & 0.000 & 0.616 & 0.000 \\
\hline LP & Stage 3 & 5.895 & 6.343 & 0.000 & 0.621 & 0.000 \\
\hline LP & Stage 4 & 7.537 & 6.956 & 0.000 & 0.614 & 0.000 \\
\hline LP & Stage 5 & 4.992 & 6.844 & 0.000 & 0.607 & 0.000 \\
\hline LP & Stage 6 & 4.615 & 6.588 & 0.000 & 0.668 & 0.000 \\
\hline
\end{tabular}

Notes: All statistics are statistically significant at $99 \%$ confidence level and that all twelve pairs of factors being tested are positively associated. Thus, a respondent who rates one factor as an important self-descriptor will also rate the other listed factor in the same row of the table as important. Therefore, all twelve research hypotheses under study are supported by the survey results.

From the test statistics, we note that all pairs of associations are statistically significant at a $99 \%$ confidence level. Therefore, a respondent who rated one factor as an important self-descriptor also rated the other listed factor in the same row of the table as being important. Thus all twelve research hypotheses were supported by the survey results as statistically significant.

We noted that among all six Kohlberg's moral development stages, the fourth stage (Maintaining Social Order) carried the strongest association with transformative leadership, and Stage 2 (Individualism and Exchange) had the least positive association. In terms of associations between specific perspectives of transformative leadership and stages of moral development, we note that the association between Charismatic Leadership and Interpersonal Relationship (Stage 3) is the strongest, with the weakest measurement being found between Level 5 leadership and Stage 3 .

\subsection{CONCLUSIONS AND CONTRIBUTIONS OF OUR PAPER}

The findings from our research do not suggest conclusive proof about the nature of leadership or the correlation between transformative leadership and the moral tendencies of leaders but suggest that 
those relationships merit further study. Additionally, our paper provides five significant contributions to the literature about leadership and its moral role.

1) We provide evidence that the complex nature of leadership has significant moral ramifications related to trust, commitment, and followership. Research calling for leaders to become more moral and ethical has increased in the aftermath of a seemingly unending series of debacles in a world now dubbed "the cheating culture" (Callahan, 2004). Our research suggests that leadership attitudes and moral maturity merit closer examination

2) We affirm the value of an integrative model of moral leadership. Leadership involves a multiple set of ethical and moral elements (cf. Hosmer, 2011). The transformative leadership model addresses a multiple set of moral and ethical duties that incorporate a higher level of moral duties and obligations that are consistent with the framework developed by Kohlberg (1981).

3) We confirm the importance of transformative leadership as a leadership model worthy of further empirical research. As a leadership model that emphasizes the moral responsibilities of leaders, transformative leadership emphasizes an integrative model of leadership that transcends more simplistic models and offers a broader moral focus.

4) We integrate moral leadership behavior with the importance of creating improved human resource management systems based upon high trust. The increasing evidence by a broad range of scholars (Paine, 2003; Pfeffer, 1998; Christensen, 2013; Covey, 2004) affirms that creating organizational cultures that treat people humanely and that honor morally superior principles leads to improved performance and profitability. As Pfeffer (1998) has noted, organizations build profits by putting people first and aligning human resource management systems that demonstrate high commitment to employees and their needs.

5) We provide the opportunity for other scholars to build upon our findings. Our research findings can be built upon and superseded by additional research about the moral duties of leaders. Virtuous leadership has become a topic of increasing interest among scholars (Cameron \& Winn, 2012; Havard, 2014), and the need for additional research about the moral virtues of tomorrow's leaders is a compelling topic.

Today's leaders face difficult challenges in a world that has become technically more complex, culturally more diverse, and economically more competitive. Those who choose to lead must honor a broad set of moral duties owed to their stakeholders to create long-term wealth (Caldwell \& Hansen, 2010). Leaders who understand the moral implications of the transformative leadership model will improve the quality of their relationships with employees and enable them to build trust, increase commitment, and achieve competitive advantage (cf. Covey, 2004; Cameron, 2011). In a world where trust in leaders is disturbingly low, much more needs to be done to understand the moral duties leaders owe to others.

\section{REFERENCES}

Agresti, A. (2010). Analysis of Ordinal Categorical Data, $2^{\text {nd }}$ ed., Wiley, New Jersey.

Agresti, A. and Finlay, B. (2009). Statistical Methods for the Social Sciences, $4^{\text {th }}$ ed., Prentice-Hall, New Jersey.

Bass, B. M. (1998). Transformational leadership: Industrial, military, and educational impact, Erlbaum, Mahwah, NJ.

Baucus, M. S. and Beck-Dudley, C. L. (2005). "Designing ethical organizations: avoiding the Long-term negative effects of rewards and punishments". Journal of Business Ethics, 56(2), pp. 355-370.

Bennis, W. and Nanus, B. (2007). Leaders: Strategies for taking charge, $2^{\text {nd }}$ ed., Harper-Collins, New York. Block, P. (2013). Stewardship: Choosing service over self-interest, $2^{\text {nd }}$ ed., Berrett- Koehler, San Francisco, CA.

Brady, F. N. (1999). "A systematic approach to teaching ethics in business", Journal of Business Ethics, 19(3), pp. 309-318.

Brown, M. E. and Trevino, L. K. (2006). "Ethical leadership: a review and future directions", Leadership Quarterly, 17(6), pp. 595-616. 
Callahan, D. (2004). The Cheating Culture: Why More Americans are Doing Wrong to Get Ahead. Mariner Books, New York.

Caldwell, C. (2012). Moral Leadership: A Transformative Model for Tomorrow's Leaders. Business Expert Press, New York.

Caldwell, C., et al. (2012). "Transformative leadership: achieving unprecedented excellence", Journal of Business Ethics, 109(2), pp. 175-187.

Caldwell, C. and Hansen, M. (2010). "Trustworthiness, governance, and wealth creation", Journal of Business Ethics, 97(2), pp.173-188.

Cameron, K. S. (2011). "Responsible leadership as virtuous leadership", Journal of Business Ethics, 98(1), pp. 25-35.

Cameron, K. S. and Winn, B. (2012). "Virtuousness in organizations", In K. S. Cameron and G. M. Spreitzer (eds.), The Oxford Handbook of Positive Organizational Scholarship, pp. 231-243. Oxford University Press, Oxford.

Christensen, C. M., (2011). The Innovator's Dilemma: The Revolutionary Book that will Change How You Do Business. New York: HarperBusiness.

Collins, J. (2008). “Celebrity leadership”, Leadership Excellence, 25(1), p. 20.

Collins, J. (2001). Good to Great: Why Some Companies Make the Leap and Others Don't. Harper Collins, New York.

Conger, J. A. and Kanungo, R. N. (1998). Charismatic Leadership in Organizations. SAGE Publications, Los Angeles.

Covey, S. R. (2004). The $8^{\text {th }}$ Habit: From Effectiveness to Greatness. Free Press, New York.

Covey, S. R. et al. (1999). First Things First: To Live, to Love, to Learn, and to Leave a Legacy. Simon \& Schuster, New York.

Donaldson, T. and Dunfee, T. W. (1999). Ties that Bind: A Social Contracts Approach to Business Ethics. Harvard Business School Press, Boston, MA.

Dubrin, A. (2013). Handbook of Research on Crisis Leadership in Organizations. Edward Elgar original Reference, Northampton, MA.

Gilligan, C. (1993). In a Different Voice: Psychological Theory and Women's Development. Harvard Business School Press, Boston, MA.

Grant, A. M. (2012). "Leading with meaning: beneficiary contact, prosocial impact, and the performance effects of transformational leadership", Academy of Management Journal, 55(2), pp. 458-476.

Havard, A. (2014). Virtuous Leadership: An Agenda for Personal Excellence. Scepter Publishers, New Rochelle, New York.

Hayibor, S. et al. (2011). "Value congruence and charismatic leadership in CEO-top manager relationships: an empirical investigation", Journal of Business Ethics, 102(2), pp. 237-254.

Hosmer, L. T. (2011). The Ethics of Management: A Multidisciplinary Approach, $7^{\text {th }}$ ed., Richard D. Irwin, New York.

Jackson, R. et al. (2013). "The dissolution of ethical decision-making in organizations: a comprehensive review and model", Journal of Business Ethics, 116(2), pp. 233-250.

Keith, K. M. (2012). The Case for Servant Leadership, $2^{\text {nd }}$ ed., Terrace Press, Chicago, IL.

Kohlberg, L. (1981). Essays on Moral Development, Vol. 1: The Philosophy of Moral Development, Harper \& Row, San Francisco, CA.

Kouzes, J. M. and Posner, B. Z. (2011). Credibility: How Leaders Gain and Lose it, Why People Demand it. Jossey-Bass, San Francisco.

Kracher, B. and Marble, R. (2008). "The significance of gender in predicting the cognitive moral development of business practitioners using the sociomoral reflection objective measure", Journal of Business Ethics, 78(4), pp. 503-526.

Lennick, D. and Kiel, F. (2007). Moral Intelligence: Enhancing Business Performance and Leadership Success. Wharton Business School Publishing, Upper Saddle River, NJ.

Lewis, C. S. (1980). Mere Christianity. Harper Collins, New York.

Lussier, R. N. and Achua, C. F. (2013). Leadership: Theory, application, and skill development, $4^{\text {th }}$ ed., SouthWestern, Mason, $\mathrm{OH}$.

Minnameier, G. (2006). “Measuring moral progress”, Journal of Adult Development, 116(3), pp. 131-143. 
Moroney, S. K. (2006). "Higher stages? Some cautions for Christian integration with Kohlberg's Theory", Journal of Psychology \& Theology, 34(4), pp. 361-371.

Parris, D. L. and Peachey, J. W. (2013). "a systematic literature review of servant leadership theory in organizational contexts", Journal of Business Ethics, 113(3), pp. 377-393.

Pava, M. (2003). Leading with Meaning: Using Covenantal Leadership to Build a Better Organization. Palgrave Macmillan, New York.

Pfeffer, J. (1998). The Human Equation: Building Profits by Putting People First. Harvard Business School Press, Boston, MA.

Reed, D. C. (2008). "A model of moral stages”, Journal of Moral Education, 37(3), pp. 357-376.

Reed, D. C. (2009). "A multi-level model of moral functioning revisited”, Journal of Moral Education, 38(3), pp. 299-313.

Sachdeva, S. et al., (2011). "Culture and the quest for universal principles in moral reasoning", International Journal of Psychology, 46(3), pp. 161-176.

Schein, E. A. (2010). Organizational Culture and Leadership. San Francisco, CA: Jossey-Bass.

Schein, E. A. (2013). Humble Inquiry: The Gentle Art of Asking Instead of Telling. Berrett-Koehler, New York.

Senge, P. M. (2006). The Fifth Discipline: The Art \& Practice of the Learning Organization. Crown Publishing, New York.

Solomon, R. C. (1992). Ethics and Excellence: Cooperation and Integrity in Business. Oxford University Press, New York.

Warrick, D. D. (2011). "The urgent need for skilled transformational leaders: integrating transformational leadership and organization development”, Journal of Leadership, Accountability, \& Ethics, 8(5), pp. 11-26.

Weber, J. (1991). "Adapting Kohlberg to enhance the assessment of managers' moral reasoning", Business Ethics Quarterly, 1(3), pp. 293-318. 